University of Nebraska - Lincoln

DigitalCommons@University of Nebraska - Lincoln

9-1995

\title{
Stress evolution during the growth of ultrathin layers of iron and iron silicide on $\mathrm{Si}(111)$
}

D. Sander

Max-Planck-Institut für Mikrostrukturphysik, Weinberg 2, 06120-Halle, Germany

Axel Enders

University of Nebraska at Lincoln, a.enders@me.com

J. Kirschner

Max-Planck-Institut für Mikrostrukturphysik, Weinberg 2, 06120-Halle, Germany

Follow this and additional works at: https://digitalcommons.unl.edu/physicsenders

Part of the Physics Commons

Sander, D.; Enders, Axel; and Kirschner, J., "Stress evolution during the growth of ultrathin layers of iron and iron silicide on $\mathrm{Si}(111) "$ (1995). Axel Enders Publications. 18.

https://digitalcommons.unl.edu/physicsenders/18

This Article is brought to you for free and open access by the Research Papers in Physics and Astronomy at DigitalCommons@University of Nebraska - Lincoln. It has been accepted for inclusion in Axel Enders Publications by an authorized administrator of DigitalCommons@University of Nebraska - Lincoln. 


\title{
Stress evolution during the growth of ultrathin layers of iron and iron silicide on $\mathrm{Si}(111)$
}

\author{
D. Sander, ${ }^{\text {a) }}$ A. Enders, and J. Kirschner \\ Max-Planck-Institut für Mikrostrukturphysik, Weinberg 2, 06120-Halle, Germany
}

(Received 4 May 1995; accepted for publication 18 July 1995)

\begin{abstract}
Using a simple optical deflection technique, we measured continuously the mechanical stress during the growth of Fe films of $0.1-1.5 \mathrm{~nm}$ thickness on $\mathrm{Si}(111)$ in ultrahigh vacuum (UHV). The stress versus coverage dependence is discussed in view of the different growth modes during the various stages of Fe deposition. The deposition of up to $0.3 \mathrm{~nm}$ Fe induces a compressive stress of $-1 \mathrm{~N} / \mathrm{m}$. We assign this stress to the formation of a reactive $\mathrm{Fe}-\mathrm{Si}$ interface layer with a silicidelike structure. Subsequent Fe deposition at $300 \mathrm{~K}$ leads to a small tensile stress of $0.7 \mathrm{~N} / \mathrm{m}$, whereas the deposition at $600 \mathrm{~K}$ induces a high tensile film stress of $18 \mathrm{~N} / \mathrm{m}$. At $600 \mathrm{~K}$ substrate temperature, a solid-state reaction between $\mathrm{Fe}$ and $\mathrm{Si}$ sets in, and the silicide $\beta-\mathrm{FeSi}_{2}$ is formed. The decrease of the atomic volume of $\mathrm{Si}$ by $7 \%$ in this silicide is proposed to be the cause for the tensile stress. (C) 1995 American Institute of Physics.
\end{abstract}

A broad range of experimental techniques has been applied to examine the iron-silicon interface and the silicide film. The semiconducting $\beta-\mathrm{FeSi}_{2}$ attracted special interest due to its reported direct energy gap of $0.89 \mathrm{eV} .^{1,2}$ To name a few techniques, low energy diffraction (LEED), ${ }^{3-7}$ reflection high energy electron diffraction (RHEED) ${ }^{8-11}$ Auger electron spectroscopy (AES) combined with electron energy loss spectroscopy (EELS), ${ }^{12-16}$ Rutherford backscattering spectroscopy (RBS), ${ }^{17}$ transmission electron microscopy (TEM), ${ }^{18,19}$ photoelectron spectroscopy, ${ }^{20-23}$ and recently scanning tunneling microscopy (STM) ${ }^{24,25}$ experiments have been performed to characterize the structural and electronic properties of the $\mathrm{Fe} / \mathrm{Si}$ system. To elucidate the issues of lattice distortion between silicon and silicide, ${ }^{3,8}$ we measured the film stress with submonolayer sensitivity during the growth of $\mathrm{Fe}$ on $\mathrm{Si}$ at temperatures between 160 and $600 \mathrm{~K}$. Our results support the more recent scenarios for the growth of $\mathrm{Fe}$ on $\mathrm{Si}$ proposed by Alvarez et al. ${ }^{24}$ favoring a reactive $\mathrm{Fe} / \mathrm{Si}$ interface even at $300 \mathrm{~K}$.

The experiments were carried out in an ultrahigh vacuum (UHV) chamber equipped with a Fe evaporator, Feflux monitor, and a quartz microbalance for calibrating the Fe-growth rates. Thus, both growth rate and film thickness were highly reproducible to within $1 \%$. Using the magnetooptical Kerr effect (MOKE), the magnetic properties of the films could be measured in situ. The rectangular shaped Si(111) samples $\left(15 \times 5 \mathrm{~mm}^{2}\right)$ were cut from a double side polished wafer of $0.15 \mathrm{~mm}$ thickness. Samples were cleaned by heating to $1300 \mathrm{~K}$ under UHV conditions. Accordingly, all experiments were done on a clean $\mathrm{Si}(111)-7 \times 7$ reconstructed surface, as checked by AES and LEED. No distinct diffraction patterns were observed for the grown films. Figure 1 shows a schematic of the stress measurement setup. Details of our compact optical beam deflection technique can be found elsewhere. ${ }^{26}$ The well-known relation ${ }^{27,28}$ between stress $\sigma$ and the experimentally determined sample curvature $R$ was used to calculate the stress:

${ }^{\text {a)} E l e c t r o n i c ~ m a i l: ~ s a n d e r @ m p i-m s p-h a l l e . m p g . d ~}$

$$
\sigma=\frac{E t_{s}^{2}}{6 R(1-\nu) t_{f}}
$$

Here, the elastic properties of the sample are $E /(1-\nu)$ $=2.2 \times 10^{11} \mathrm{~N} / \mathrm{m}^{2}$ for $\mathrm{Si}(111),{ }^{29}$ the sample thickness is given by $t_{s}=0.15 \mathrm{~mm}$, and $t_{f}$ denotes the film thickness. The measured stress value is attributed to the homogeneously Fecovered length of the sample, as checked by AES. An overall error bar of $\pm 10 \%$ must be considered for all quoted stress values, due to the uncertainties in the relevant dimensions. We prefer to speak of surface stress of the substrate, defined by $\sigma_{\text {surf }}=\sigma t_{f}$ in units of $\mathrm{N} / \mathrm{m},{ }^{30,31}$ as the ultrathin limit, a film thickness is hard to define. Typical surface stress values are 1 $\mathrm{N} / \mathrm{m}$. Assigning this stress to a layer of $0.1 \mathrm{~nm}$ thickness gives a tremendous film stress of $10 \mathrm{GPa}$, which is beyond the elasticity region of steel. Nevertheless, the resulting displacement of the end of the sample amounts to only $50 \mathrm{~nm}$, but this minute effect is easily detected. Even higher sensitivities can be obtained by capacitance ${ }^{30-32}$ or more sophisticated optical methods. $^{33,34}$

In Fig. 2 we present stress measurements for the growth of $\mathrm{Fe}$ on $\mathrm{Si}(111)$ at $300 \mathrm{~K}$. The surface stress was monitored

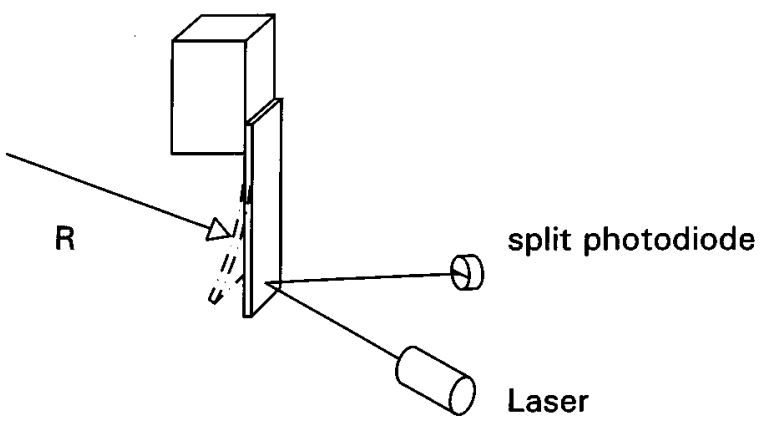

FIG. 1. The top of the sample is attached to the sample holder, the bottom end is free. The radius of curvature $R$ of the sample is monitored by reflecting the laser beam from the sample surface to a split photodiode. Any stress on the sample surface will cause the sample to bend, thus giving rise to a position signal at the split photodiode. 


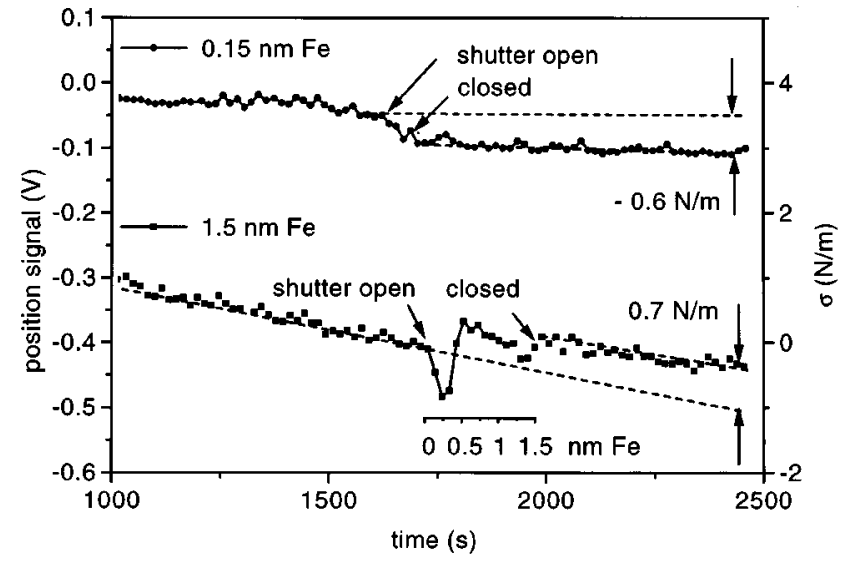

FIG. 2. Stress measurements taken during the deposition of 0.15 and $1.5 \mathrm{~nm}$ $\mathrm{Fe}$ on $\mathrm{Si}(111)$. The growth rate was $0.4 \mathrm{~nm} / \mathrm{min}$ at $T_{\mathrm{Si}}=300 \mathrm{~K}$. Stress values are obtained by measuring the offset of the position signal between the clean and the Fe-covered sample.

for some time and at the indicated times, the shutter of the $\mathrm{Fe}$ evaporator was opened. In our experiments, a negative position signal indicates a compressive stress. For the first 0.3 $\mathrm{nm}$ of $\mathrm{Fe}$, a compressive stress of $-1 \mathrm{~N} / \mathrm{m}$ is measured, as shown in the lower curve in Fig. 2. For increasing Fe coverages, a tensile stress sets in that compensates for the initial compressive stress. Further deposition of $\mathrm{Fe}$ up to $1.5 \mathrm{~nm}$ creates a very small tensile stress of $0.7 \mathrm{~N} / \mathrm{m}$. Note the top curve in Fig. 2. Here, for a small deposition of up to $0.15 \mathrm{~nm}$ $\mathrm{Fe}$, a compressive stress of $-0.6 \mathrm{~N} / \mathrm{m}$ is measured. We propose the formation of an intermixed $\mathrm{Fe}-\mathrm{Si}$ layer to be responsible for the compressive stress. Our LEED experiments showed a strongly increased background intensity with weak $1 \times 1$ spots, even for small Fe coverages. The absence of the distinct diffraction pattern is in line with a surface reaction which destroys the long-range periodicity by creating $\mathrm{FeSi}$ like patches on the surface. As our measurement of $0.15 \mathrm{~nm}$ $\mathrm{Fe}$ deposition shows, the compressive stress is maintained in the surface unless more than $0.3 \mathrm{~nm}$ of $\mathrm{Fe}$ is deposited. We conclude that there must be a change in the growth mode from $0.3 \mathrm{~nm}$ Fe thickness on. Comparing our results to a recent STM, UPS, ISS study by Alvarez et al. ${ }^{24}$ the compressive stress regime can be attributed to the creation of the reactive $\mathrm{Fe}-\mathrm{Si}$ interface, while the tensile stress regime is attributed to the growth of Fe islands on top of this FeSi-like layer. The formation of a $\mathrm{FeSi}$ - or $\mathrm{Fe}_{3} \mathrm{Si}$-like interfacial layer is a plausible explanation for the compressive stress, as in both compounds, the atomic volume per $\mathrm{Si}$ atom is considerably increased. ${ }^{35,36}$ Surplus Si atoms are forced out of their regular lattice positions in new interstitial or surface positions. ${ }^{24}$ The so-called interstitials might play a significant role at the silicide formation at $600 \mathrm{~K}$ (Ref. 36), which will be discussed below.

We assign the tensile stress for $\mathrm{Fe}$ coverages above 0.3 $\mathrm{nm}$, to the growth of $3 d$-Fe-crystallites on top of this amorphous interface. This growth mode is in keeping with our AES investigations at $300 \mathrm{~K}$ and is known to cause tensile stress, as a result of the merging of grain boundaries. ${ }^{32} \mathrm{In}$ addition, further tensile contributions to the stress might be expected from comparing the interatomic distances in $\mathrm{Fe}$ to

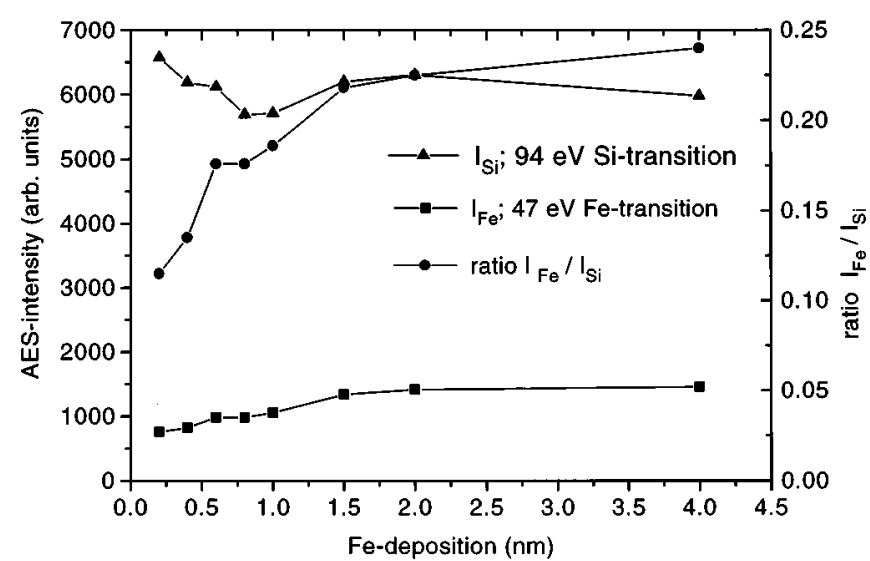

FIG. 3. Auger electron spectroscopy data taken for Fe deposition at $600 \mathrm{~K}$ substrate temperature. From $1.5 \mathrm{~nm}$ Fe deposition on, a nearly constant Auger intensity ratio of $I_{\mathrm{Fe}} / I_{\mathrm{Si}}=0.23$ is measured.

the values in a silicide. For all silicides, the interatomic distances are larger than for pure Fe. ${ }^{35}$ Thus, even for $3 d$-growth, we expect some tensile stress directly at the Fesilicide interface.

At the $600 \mathrm{~K}$ substrate temperature, a solid-state reaction between the Fe film and Si-substrate sets in during deposition. The most obvious proof for this reactive deposition epitaxy is obtained by doing an AES-intensity study of the Fe $47 \mathrm{eV}$ and the Si $94 \mathrm{eV}$ peaks. In Fig. 3 we present the Fe, Si, and the $\mathrm{Fe} / \mathrm{Si}$ intensity ratio as a function of $\mathrm{Fe}$ thickness. From our data, a Fe/Si ratio of $\sim 0.23$ is extracted. This $\mathrm{Fe} / \mathrm{Si}$ intensity ratio is characteristic of a $\mathrm{FeSi}_{2}$ stoichiometry using our AES data. Furthermore, under these growth conditions the formation of $\mathrm{FeSi}_{2}$ has been reported by Gallego and Miranda. ${ }^{14}$ As our silicide films do not show any ferromagnetic behavior, as checked by in situ magneto-optical Kerr effect measurements, we exclude the formation of the magnetic $\gamma \mathrm{FeSi}_{2}{ }^{9}$ This leaves the semiconducting $\beta$ - $\mathrm{FeSi}_{2}$ as the phase formed. We obtain the same AES signal ratio after annealing a $4 \mathrm{~nm}$ Fe layer, deposited at 160 or $300 \mathrm{~K}$, for 20 $\min$ at $600 \mathrm{~K}$. This silicide formation at a rather low temperature indicates the high mobility of $\mathrm{Si}$ in the deposited $\mathrm{Fe}$ film. Lau et al. ${ }^{37}$ have shown that $\mathrm{Si}$ is the moving species during the formation of the Fe silicide.

In Fig. 4, we present data on the stress caused by the silicide formation at $600 \mathrm{~K}$. To elucidate the kinetic parameters, growth rates of 0.4 and $0.1 \mathrm{~nm} / \mathrm{min}$ were used. The interface formation during the first $0.3 \mathrm{~nm}$ of $\mathrm{Fe}$ deposition is characterized by a compressive stress, as discussed above for growth at $300 \mathrm{~K}$. In contrast to the experiments done at 300 $\mathrm{K}$, further $\mathrm{Fe}$ deposition at $600 \mathrm{~K}$ leads to the formation of $\beta-\mathrm{FeSi}_{2}$ on top of this interface layer. During the silicide formation we measure a huge tensile stress of 11.2 and 18 $\mathrm{N} / \mathrm{m}$ for the high and low growth rates, respectively.

We suggest a qualitative explanation for the tensile stress in the formed $\beta-\mathrm{FeSi}_{2}$ layer based on the decreased atomic volume of $\mathrm{Si}^{35,38}$ in this silicide film. Thus, as a net effect of the silicide formation, each Si atom occupies $18.7 \AA^{3}$ instead of $20.07 \AA^{3}$, thereby inducing a tensile film stress. The Fe atoms do not enter this simplified picture, as we assume that 


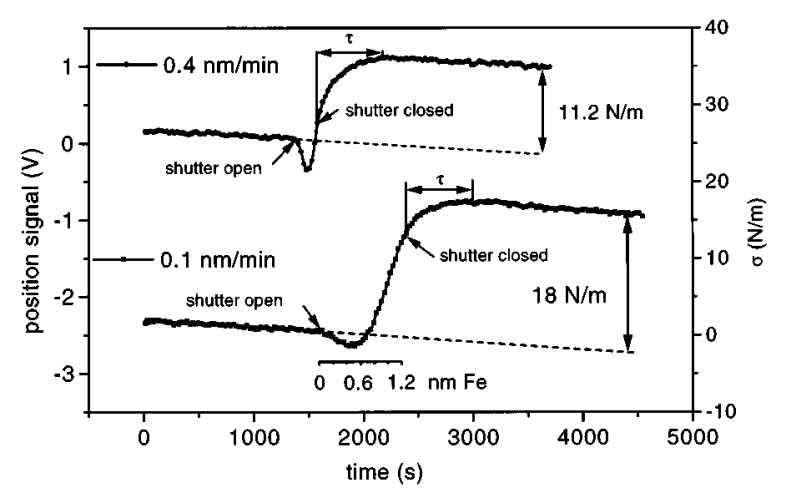

FIG. 4. Stress measurements taken during the silicide formation. Fe was deposited on a $\mathrm{Si}(111)$ sample heated to $600 \mathrm{~K}$. For fast and slow growth rates, the same amount of time $\tau$ passes, until the stress vs time curve returns to the thermal drift line.

the arriving $\mathrm{Fe}$ atoms are more or less directly bonded in Fe-silicide positions. The abundancy of Si atoms at the film surface, ${ }^{14}$ even during growth, ensures this bonding mechanism. In addition to the $\mathrm{Si}$ interstitials created right at the interface during the early stages of growth, ${ }^{36}$ further easydiffusion channels are likely to be formed by stress induced lattice defects in the silicide film or in the silicon substrate. Thus, an abundant supply of $\mathrm{Si}$ atoms seems plausible. As we measure stress during a reactive deposition of $\mathrm{Fe}$, our results cannot be explained by an existing stress model. ${ }^{39} \mathrm{In}$ contrast to our experiments, this model, as most stress measurements do, ${ }^{39}$ start from a metal-Si compound, which reacts to form a silicide.

From the stress versus time plots in Fig. 4 some important facts on the kinetics and relaxation processes of the silicide formation can be learned. At the higher growth rate, the stress continues to increase rapidly for the first $60 \mathrm{~s}$ after the shutter has been closed, whereas as the lower growth rate, the stress increase slows down at the moment the flux of $\mathrm{Fe}$ is terminated. We suggest that at the higher growth rate the flux of $\mathrm{Si}$ atoms to the surface is not sufficient to create the energetically favorable $\mathrm{FeSi}_{2}$ stoichiometry instantaneously. The unreacted $\mathrm{Fe}$ undergoes its transition to $\mathrm{FeSi}_{2}$ during the first $60 \mathrm{~s}$ after completion of the $\mathrm{Fe}$ deposition. A further contribution to the stress increase, valid for both rates, is assigned to a structural reorientation, that might be driven by achieving a local $\beta-\mathrm{FeSi}_{2}$ structure as perfect as possible. The lower final stress of $11.2 \mathrm{~N} / \mathrm{m}$ measured for growth at higher rates compared to $18 \mathrm{~N} / \mathrm{m}$ measured at the lower rate indicates an incomplete reaction of the Fe atoms for deposition at higher rates.

In conclusion, our stress measurements clearly show, how different growth modes and solid-state reactions can be identified by a characteristic stress behavior. Thus, stress measurements contribute important information on the atomistic processes at interfaces and thin films.
${ }^{1}$ M. I. Bost and J. E. Mahan, J. Appl. Phys. 58, 2696 (1985).

${ }^{2}$ M. I. Bost and J. E. Mahan, J. Appl. Phys. 64, 2034 (1988).

${ }^{3}$ D. R. Peale, R. Haight, and J. Ott, Appl. Phys. Lett. 62, 1402 (1993).

${ }^{4}$ T. Urano and T. Kanaji, Appl. Surf. Sci. 33/34, 68 (1988).

${ }^{5}$ F. Scarinci, S. Lagomarsino, C. Giannini, G. Savelli, P. Castrucci, A. Rodia, and L. Scopa, Appl. Surf. Sci. 56-58, 444 (1992).

${ }^{6}$ S. Kennou, N. Cherief, R. C. Cinti, and T. A. Nguyen Tan, Surf. Sci. 211/212, 685 (1989).

${ }^{7}$ J. W. Ridgway and D. Haneman, Surf. Sci. 24, 451 (1971).

${ }^{8}$ J. Derrien, J. Chevrier, V. Le Thanh, and J. E. Mahan, Appl. Surf. Sci. 56-58, 382 (1992).

${ }^{9}$ N. Onda, J. Henz, E Müller, K. A. Mäder, and H. von Känel, Appl. Surf. Sci. 56-58, 421 (1992).

${ }^{10}$ J. Chevrier, V. Le Thanh, S. Nitsche, and J. Derrien, Appl. Surf. Sci. 56-58, 438 (1992).

${ }^{11}$ J. E. Mahan, K. M. Geib, G. Y. Robinson, R. G. Long, Y. Xinghua, G. Bai, M. A. Nicolet, and M. Nathan, Appl. Phys. Lett. 56, 2126 (1990).

${ }^{12}$ H. Moritz, B. Rösen, S. Popovic', A. Rizzi, and H. Lüth, J. Vac. Sci. Technol. B 10, 1704 (1992).

${ }^{13}$ X. Wallart, H. S. Zeng, J. P. Nys, and G. Dalmai, Appl. Surf. Sci. 56-58, 427 (1992).

${ }^{14}$ J. M. Gallego and R. Miranda, J. Appl. Phys. 69, 1377 (1991).

${ }^{15}$ A. Rizzi, H. Moritz, and H. Lüth, J. Vac. Sci. Technol. A 9, 912 (1991).

${ }^{16}$ Q. G. Zhu, H. Iwasaki, E. D. Williams, and R. L. Park, J. Appl. Phys. 60, 2629 (1986)

${ }^{17}$ C. Schwarz, N. Onda, S. Goncalves-Conto, H. Sirringhaus, and H. von Känel, J. Appl. Phys. 76, 7256 (1994).

${ }^{18}$ X. W. Lin, M. Behar, J. Desimoni, H. Bernas, J. Washburn, and Z. Liliental-Weber, Appl. Phys. Lett. 63, 105 (1993).

${ }^{19}$ N. Cherief, C. D'Anterroches, R. C. Cinti, T. A. Nguyen Tan, and J. Derrien, Appl. Phys. Lett. 55, 1671 (1989).

${ }^{20}$ J. Alvarez, J. J. Hinarejos, E. G. Michel, and R. Miranda, Surf. Sci. 287/ 288, 490 (1993).

${ }^{21}$ J. M. Gallego, J. M. Garcia, J. Alvarez, and R. Miranda, Phys. Rev. B 46, 13339 (1992).

${ }^{22}$ J. Alvarez, J. J. Hinarejos, E. G. Michel, G. R. Castro, and R. Miranda, Phys. Rev. B 45, 14042 (1992).

${ }^{23}$ M. D. DeCrescenzi, G. Gaggiotti, N. Motta, F. Patella, F. Balzarotti, and J. Derrien, Phys. Rev. B 42, 5871 (1990).

${ }^{24}$ J. Alvarez, A. L. Vazquez de Parga, J. J. Hinarejos, J. De La Figuera, E. G. Michel, C. Ocal, and R. Miranda, Phys. Rev. B 47, 16048 (1993).

${ }^{25}$ A. L. Vazquez de Parga, J. De La Figuera, C. Ocal, and R. Miranda, Europhys. Lett. 18, 595 (1992).

${ }^{26}$ D. Sander, A. Enders, and J. Kirschner, Ref. Sci. Instrum. (to be published).

${ }^{27}$ A. Brenner and S. Senderoff, J. Res. Natl. Bur. Stand. 42, 105 (1949).

${ }^{28}$ G. G. Stoney, Proc. R. Soc. London Ser. A 82, 172 (1909).

${ }^{29}$ W. A. Brantley, J. Appl. Phys. 44, 534 (1972).

${ }^{30}$ D. Sander and H. Ibach, Phys. Rev. B 43, 4263 (1991).

${ }^{31}$ D. Sander, U. Linke, and H. Ibach, Surf. Sci. 272, 318 (1992).

${ }^{32}$ R. Koch, J. Phys. Condens. Matter. 6, 9519 (1994).

${ }^{33}$ A. J. Shell-Sorokin and R. M. Tromp, Phys. Rev. Lett. 64, 1039 (1990).

${ }^{34}$ R. E. Martinez, W. A. Augustyniak, and J. A. Golovchenko, Phys. Rev. Lett. 64, 1035 (1990).

${ }^{35}$ B. Eggert and G. Panzner, Phys. Rev. B 29, 2091 (1984).

${ }^{36}$ M. Ronay and R. G. Schad, Phys. Rev. Lett. 64, 2042 (1990).

${ }^{37}$ S. S. Lau, J. S.-Y. Feng, J. O. Olowolafe, and M.-A. Nicolet, Thin Solid Films 25, 415 (1975).

${ }^{38}$ Y. Dusausoy, J. Protas, R. Wandji, and B. Roques, Acta Crystallogr. Sect. B 27, 1209 (1971).

${ }^{39}$ S.-L. Zhang and F. M. d'Heurle, Thin Solid Films 213, 34 (1992). 